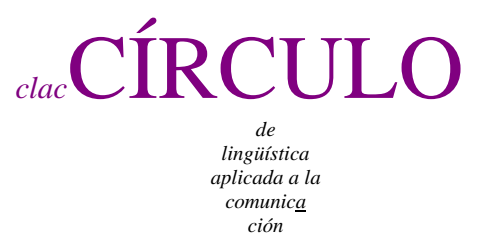

$65 / 2016$

\title{
DISCOURSE CHANGE IN A CHANGING SOCIETY: \\ A CRITICAL DISCOURSE ANALYSIS OF POLITICAL ADVERTISEMENT \\ IN JORDAN BEFORE AND AFTER THE ARAB SPRING
}

\author{
Kawakib Al-Momani \\ Jordan University of Science and Technology \\ kmomani at just edu jo
}

\begin{abstract}
This study provides a critical discourse analysis of election advertisements in Jordanian society before and after the political uprisings in the Arab world, referred to as the "Arabic Spring", which started in 2011. It is argued here that these events have left traces on political advertisement. This study aims to uncover the shifts in discourse that have occurred in election advertisements since 2011. To this end, a sum of 150 advertisements from three election campaigns 2007, 2010 and 2013 was collected from different media sources during the campaigns of those elections. The data were analyzed both qualitatively and quantitatively. The analysis showed that the advertisements of 2013 elections manifested different strategies, addressing mostly sociopolitical issues, compared to the other two elections which showed little political concern and focused on socio-economic issues. It is hoped that this study will contribute to cross cultural understanding, multimodality and critical discourse analysis.
\end{abstract}

Key words: Elections, advertisements, social change, political change, discourse change, experiential, relational, expressive, textual values

Kawakib Al-Momani. 2016.

Discourse Change in a Changing Society: a critical discourse analysis of political advertisement in Jordan before and after the Arab Spring Círculo de Lingüística Aplicada a la Comunicación 65, 3-43.

http://www.ucm.es/info/circulo/no65/almomani.pdf

http://revistas.ucm.es/index.php/CLAC

http://dx.doi.org/10.5209/rev_CLAC.2016.v65.51980

(C) 2016 Kawakib Al-Momani

Círculo de Lingüística Aplicada a la Comunicación (clac)

Universidad Complutense de Madrid. ISSN 1576-4737. http://www.ucm.es/info/circulo 
Contents

1. Introduction 5

2. Literature review 7

2.1. Advertisement and social change 7

2.2. Advertisement and background knowledge 7

2.3. Political advertisement 8

3. Theoretical background 9

3.1. Multimodal critical discourse analysis 9

3.2. Interpretation of discourse 10

4. Methodology 12

5. Analysis and interpretation of results 12

5.1. Experiential values 12

5.1.1. New emerging words 17

5.1.2. Visual techniques 18

5.2. Relational values 20

5.2.1. Inclusion 21

5.2.2. Exclusion 23

5.2.3. Creating positive and negative images 24

5.3. Expressive values 26

5.3.1. Intertextual borrowings 26

5.3.2. Religious borrowings 27

5.3.4. Poetic borrowings 30

5.3.5. Socio-Cultural references 30

5.4. Textual values 31

6. Conclusion 33

References 34

Annex 1: Visual symbols commonly used in election advertisement in Jordan in 2007 37

Annex 2: Symbols in 2010 election advertisement in Jordan 39

Annex 3: Symbols in 2013 election advertisement in Jordan 41 


\section{Introduction}

The present study is an extension to a previous study by the researcher (Al-Momani 2012) which investigated the schematic representations in 2007 election advertisements in Jordan. The current study is an attempt to explore the shifts in discourse that occurred in election advertisement in Jordan after the Arab political uprisings in 2011 known as the 'Arab Spring', in particular the 2013 election advertisement.

The political scene in the Arab world has witnessed dramatic fluctuations in the last few years. These fluctuations have recently taken the form of revolutions that aim to lead to a kind of transition which construes changes from more dictatorships to more democratic systems. Poverty, unemployment, political unrest, Israeli and Western hegemony and corruption scandals have generated very intense feelings of oppression and suppression, threat, fear, worry, and anger among the young Arabs and eventually led to the explosion of anguish in 2011 in most of the Arab countries. Since then the area has been under a series of dramatic changes that have resulted in the fall of the strongest Arab leaders and their regimes in the region- the Tunisian, Egyptian, Libyan and Yemeni. Other countries are not without trouble; protests and revolutions are almost everywhere. In Syria, the situation has been tragic for almost three years and a situation of civil war has been created. These uprisings have been called the Arab Spring. This is because most of the major events took place in the spring of 2011, and they were initiated by the young (those who were in the spring of their lives) through the social network known as Facebook. The Arab Spring is seen as the representation of the public feelings and desires to achieve democracy, exactly like the European widespread revolutions of 1848 which were known as the "Springtime of People" that were essentially democratic (Merriman 1996), and the liberalization movements in Czechoslovakia after World War II, known as "Prague Spring” which were a strong attempt to grant additional rights to the citizens of Czechoslovakia. 
In Jordan the situation was also sensitive. Political movements started earlier than 2011. They took the form of parades and marches led by the opposition parties in reaction to the 2007 elections which were described as a scandal because candidates counted on political money to win the elections. "In its early phase, protests in Jordan were initially against unemployment, inflation, corruption, and electoral reforms” ${ }^{1}$. However, in 2011 the protestors' demands escalated to a call for real political changes, real constitutional monarchy and real electoral reforms (Raskob 2012, Spindle, 2012) In light of all this and in the middle of the Arab spring, the $13^{\text {th }}$ parliamentary elections were run in 2013. People no longer trusted the single vote system which has sustained and reinforced tribalism in Jordanian society and deprived the country of qualified people dragging the country to the bottom and taking it many years backward. To please the public and convince them to participate, especially the opposition parties, namely Muslim Brotherhood, who have boycotted the elections since 2007 (Spath and Makara 2013), an electoral law was passed which allows the voters two votes- one for their constituency candidate and the other for a national candidate nominated in a list. In light of the absence of real organized political parties, those lists turned out to be collections of individuals with personal connections rather than organized parties. This new electoral reform law did make changes to the election process, but it did not please many people particularly the opposition parties who argued that what it did was merely cosmetic (Christophersen 2013). The extra vote was supposed to help political parties get a chance to win, but to the opposition parties these reforms did not go far enough and the constituency system still favored tribal candidates ${ }^{2}$.

All the above mentioned facts and practices were reflected in the candidates' election advertisements. Although many people and observers believe the 2013 elections were not different from previous ones, this study claims that there is a significant difference

\footnotetext{
${ }^{1}$ Protesters demand 'saving' Jordan from corruption. The Daily Star (Lebanon), 2 December 2011.

${ }^{2}$ Jordan's Muslim Brotherhood to boycott early elections. BBC News, 13 July 2012
} 
in the language of advertisement between the elections of 2013 and those of 2007 and 2010. In this paper these demarcating differences are highlighted and analyzed in this study in light of the recent political changes that have taken place in the region. The analysis is carried out within a multimodal Critical Discourse Analysis.

\section{Literature review}

The aim of advertisement is to convince people of a specific product, a service provided or an ideological stance. So it must be up to dates with changes in society at all levels, economically, politically and socially in terms of attitudes and ideologies.

\subsection{Advertisement and social change}

Advertisement reflects culture and society. It is influenced by the social, economic, and cultural environment in a given society. It reflects society and is shaped by social change and culture. Sloan (1991) recognizes advertising not only as a window to culture but also as a mirror that reflects culture. Any changes in society are reflected in the discourse of advertising. Social change and discourse change are most obvious in different fields of which the field of advertisement is one. Fairclough (2005a: 1) argues that "Social changes are changes in discourse". He argues that when there is a change in one aspect of society, other aspects are affected. So 'social change entails change in social structures, social practices and social events. This in its turn brings about changes in genres and styles which affect how elements of discourse are articulated together.' (ibid 2005 a: 6). This change, Fairclough argues, is 'realized through linguistic, semiotic and interdiscursive features of text. Social structures, of which language is one, and social events are parts of social reality which is realized in discourse' (Fairclough 2005b).

\subsection{Advertisement and background knowledge}

An (2003) studies advertisements during times of depression and argues that 'advertising is part of the changing social, economic, and cultural environment. Historical events, mundane situations and contemporary cultural values are usually 
coded in advertisement. Myers (2003) Confirms that advertisements are part of the individual's schemata which is acquired through one's prior perceptions, experiences, attitudes, social background, and cultural orientation. Once the event coded in the image is recognized, the individual tends to employ one or more schemata of interpretation. As such schematic knowledge becomes of paramount significance. Werner (2004) identifies three factors that are needed for realizing the values coded in advertisement: Shared cultural knowledge; an ideal viewer who has semiotic knowledge to draw conclusions for more subtle symbols in the image; and generic knowledge or knowledge of the social occasion or field of discourse within which the image is constructed and read (i.e. commercial be it or political). It is then that these images become meaningful.

\subsection{Political advertisement}

Political advertisement is non-commercial and is also part of the changing social environment. It reflects the society's political conditions, and 'its success depends on the ability of the advertisers to predict and to react to a changing society' (An 2003). Responding to social change, candidates, in their endeavor to win the votes of their audience, create their visuals in a way that could appeal to the voters who are concerned with and affected by the changes in their society. Their slogans also respond to the public needs and demands. Al-Momani (2012) studies political advertisements in Jordanian society and finds out that most of the slogans in 2007 elections reflected chronic socio-economic issues, such as poverty and unemployment.

Visual communication is the most important dimension of advertising. Moriarty (1986, 1987) divides visuals into two main categories. The first category is photographic or illustrative visuals; the second is literal or symbolic. If visuals are literal, they usually provide factual information which includes identification, description or demonstration (how to do, make, use, etc.). Symbolic visuals, on the other hand, are concerned with representations through the use of associations with specific personalities, life styles or situation (An 2003). 
In political advertisement the visuals are mostly photographic and are supposed to be literal, in the sense that they convey factual information about candidates. They provide identifications represented by the photo and name of the candidate, and other necessary information as the name and number of constituency. However, most political advertisements also include some symbolic visuals that represent specific ideologies or certain aspects in the candidate's personality. For example, the way he/she is dressed up, the symbol he/she adopts when a symbol is required, the size of the poster, the font of the verbal captions, the colors, and the motto of the campaign are all symbolic.

Political advertisements can be both dynamic and static (Rossiter \& Percy 1983). In their dynamic form they include debates and speeches, and in their static form, they mainly depend on visuals used in posters scattered in the streets or posted on TV screens and newspapers. The influence of these visuals depends on the poster size and duration and number of exposure. This study concerns the latter form. In this context print advertisements are analyzed both verbally and visually in light of the political changes that have recently taken place in the Arab world.

\section{Theoretical background}

\subsection{Multimodal critical discourse analysis}

Discourse shapes and is shaped by the world; accordingly verbal and visual elements present the world to us and help figure out the world around us. Multimodality is one important feature of advertising. It refers to "multiple modes of communication operating at the same time” (Kress \& Van Leeuwen 2001). The verbal and visual modes interact to create new meanings and connections. Therefore, advertisement should be analyzed holistically taking into consideration all modes. Ignoring any mode may lead to missing these new meanings and connections. That is because "people do not simply read images in isolation from verbal text that accompanies them; nor do they read the verbal text without reference to accompanying image.” (Goddard 2002: 13). O’Halloran (2008: 459) stresses this complementarity between the different semiotics in a text. She contends that "language functions to order our experiential view of the world through specific configurations of processes, participants, and circumstances. And 
visual imagery is capable of "reproducing our perceptual awareness of the world". This sort of complementarity is stressed in all research on multimodality (e.g. Iedema (2003); Cheong (2004); Stockl (2004); Royce (2007); Unsworth (2007); Bowcher (2007); O’ Halloran (2008); and Johnstone (2008) among other figures in this field).

\subsection{Interpretation of discourse}

The interpretation of the different semiotics in advertisement requires schematic cultural knowledge as advertising is a culture-based genre. You need to be communicatively competent to approach it. Living in the culture itself is one important factor, but following up the new developments of the different techniques in advertising gives you a better chance to make comparisons and pursue the developments in the field. However, schematic knowledge alone is not enough. Linguistic knowledge is also required to figure out the verbal and visual signs and their representations. The interpretation of linguistic and semiotic representations in advertisement requires a tool to uncover the different hidden discourses and understand the intersemiotic relationships. The theories of CDA provide the tools to linguistic and other forms of semiotic analysis. Linguistic analysis concerns itself with lexico-grammatical choices. Semiotic analysis, on the other hand, involves both verbal and pictorial elements and their significations.

Fairclough (1989) provides a lexico-grammatical model of CDA which comprises three levels: description, interpretation and explanation. The description stage involves the analysis of data in terms of their experiential, relational, and expressive values at the textual level within its linguistic and non-linguistic environment. Linguistically speaking, these values are reflected at three levels: lexical, structural and discoursal. At the lexical level, the experiential values examine the persuasive practices in terms of wording, rewording, overwording, and collocations. The expressive values refer to the speaker's evaluation of the bit of reality in question which is implied in the vocabulary. As for relational values, they refer to the social relationships among participants as expressed in the modes of sentence (i.e. declarative, imperative, or interrogative), modality (i.e. necessity, obligation, or probability), and pronouns (i.e. inclusion and exclusion practices). Such an evaluation includes both positive and negative 
representations. At the structural level, the experiential values show the discursive grammatical use of language which serves the speakers' ideological interests.

At the discourse level, the analysis is carried out in terms of linguistic and nonlinguistic contextual relationships. Linguistically speaking, the data are analyzed in terms of cohesion and coherence. The former is investigated to expound the relationship between sentences on the basis of reference and relationships between sentences, while the latter is examined through intertextual practices as well as schematic representation as factors that determine the communicative event and the organizational as well as schematic patterns of the text.

The interpretation stage focuses on making inferences about meanings of discourse and hence identifying the persuasive strategies in the speeches. The analysis of textual elements is followed by an interpretation of their anticipated meaning in discourse. The final stage is the explanation stage which is concerned with the social dimensions and social effects of discourse.

Van Dijk (2005) provides a multidisciplinary approach of CDA. He views the three stages in Fairclough's model as dimensions of analysis comprising discourse, cognition, and society. The description stage which focuses on textual and linguistic analysis forms only one dimension of analysis; that is the 'discourse dimension'. To understand the message behind a given text, the other two dimensions are deemed necessary: the 'cognitive dimension' which is concerned with processing the material and interpreting meanings; and the 'social dimension' which deals with relating the meanings interpreted with society. The interpretation stage in Fairclough's model involves the cognitive dimension of discourse, and the explanation stage involves the social dimension.

Since the main concern of this study is to investigate the shifts in the language of advertisement in 2013 elections, it provides an interpretation of meanings and relates them with social change. The analysis aims to show how language is utilized and manipulated to reflect these changes and how they manipulate people's minds and feelings. 


\section{Methodology}

150 election advertisements were collected during the election campaigns of 2007, 2010 and 2013 from different media sources (e.g. newspaper, flyers and street posters). Based on Fairclough's (1989) and Van dijk's (2005) models of CDA, a simplified model is attempted here to analyze the data for this study. The analysis starts with a quantitative descriptive analysis to provide statistics of verbal and non-verbal recurrences in the sample data to uncover the fluctuations in the linguistic and textual patterns and recurrences in the advertisements of the three elections. The linguistic level focuses on experiential, relational and expressive values. Experiential values are reflected in the lexical choices represented by synonyms and collocations. Relational values reflect the social relationships between the participants which are evident in the practices of solidarity, inclusion and exclusion as expressed through mood, modality and pronouns. And expressive values concern the producer's evaluation of reality as reflected in the choice of linguistic elements. The textual level concerns the generic moves and distribution of information and intertextual borrowings.

The quantitative analysis is followed by a qualitative discursive analysis to provide an interpretation of the meanings behind the quantitative analysis. An explanation that relates them to the socio-cultural values in Jordanian society and to the current political situation in the region is then provided.

\section{Analysis and interpretation of results}

The linguistic analysis focuses on experiential, relational and expressive values of the lexical choices in the advertisements of the three elections.

\subsection{Experiential values}

Experiential values relate to the representation of the producer's experience of the natural and social world (Fairclough, 1989). These values are reflected through verbal techniques represented in lexical choices including synonymy and collocations. They also include visual choices including photos and symbolic images. The analysis of the 
data has revealed that there are common lexical items that are used in the advertisements of the three elections but with different frequency. Table (1) shows the recurrence of common lexical items used in the advertisements of the three elections 2007, 2010, and 2013 and their frequency in percentages.

Table (1) Frequency of common synonyms of patriotism in the advertisements of the three elections 2007, 2010 and 2013

\begin{tabular}{|l|l|l|l|l|}
\hline $\begin{array}{l}\text { Lexical Item } \\
\text { Arabic }\end{array}$ & English & $\begin{array}{l}2007 \\
\%\end{array}$ & $\begin{array}{l}2010 \\
\%\end{array}$ & $\begin{array}{l}2013 \\
\%\end{array}$ \\
\hline Urdun & Jordan & $15 \%$ & $10 \%$ & $1 \%$ \\
\hline Wattan & Country/home & $15 \%$ & $18 \%$ & $11 \%$ \\
\hline Wihdah & Unity & $9 \%$ & $8 \%$ & $11 \%$ \\
\hline Wafa? wa intima? & Sincerity and loyalty & $3 \%$ & $4 \%$ & $1 \%$ \\
\hline Malik & King & $3 \%$ & $6 \%$ & $1 \%$ \\
\hline & & $45 \%$ & $36 \%$ & $25 \%$ \\
\cline { 4 - 5 } & & &
\end{tabular}

As can be seen from table (1), synonyms of words which convey patriotic meanings (henceforth patriotic words) were more recurrent in the advertisements of 2007 elections than they were in those of 2010 and 2013. They were minimally used in 2013 election advertisements. The use of patriotic words dropped from 45\% in 2007 to 36\% in 2010 and to 25\% in 2013. Words like Jordan, Sincerity and loyalty, and country/home were the most recurrent in 2007, followed by words connoting solidarity, such as solidarity and unity.

In light of the increasing immigration from neighboring countries which have political conflicts and in the absence of political vision on the part of both the candidates and the voters, patriotism has become an important factor in election advertisements in Jordan. Expressions of loyalty and belonging were most obvious in 2007 election advertisements. This continued in 2010 but at a smaller scale than in 2007 due to the fact that people were not pleased with the voting system that resulted in 2007 elections. A situation of unrest was then created that was manifested in marches and demonstrations calling for political reforms as a reaction to the scandalous elections of 2007 denounced for candidates' reliance on tribal affiliation and use of political money 
to win. However, with the political changes in the Arab region in 2011 and the corruption scandals that were revealed afterwards, people became aware that more national issues need to be addressed in their quest for democracy. Questioning those in authority, who have been accused of robbing the public, is one of the public demands in 2013 election advertisements. This indicates the public will to change. New demands such as achieving justice, preserving people's rights, and enjoying real democratic life represented by power exchange and real political changes have emerged. These represent the wishes of the new generation which the advertisement of 2013 elections reflects. Table (2) shows the frequency of the synonyms of words that mark a change (henceforth words of change) in the linguistic selection in advertisements of the three elections

Table (2) frequency of Synonyms of change in the advertisements of the three elections 2007, 2010 and 2013

\begin{tabular}{|l|l|l|l|l|}
\hline $\begin{array}{l}\text { Lexical Item } \\
\text { Arabic }\end{array}$ & English & $\begin{array}{l}2007 \\
\%\end{array}$ & $\begin{array}{l}2010 \\
\%\end{array}$ & $\begin{array}{l}2013 \\
\%\end{array}$ \\
\hline Mustaqbal afdal & Better future & $9 \%$ & $2 \%$ & ------ \\
\hline Taghier & Change & $6 \%$ & $8 \%$ & $13 \%$ \\
\hline Wa d wa ahd & Promise and vow & $6 \%$ & $4 \%$ & $1 \%$ \\
\hline Muharabat alfasad & Fighting corruption & $3 \%$ & $2 \%$ & $15 \%$ \\
\hline adalah & Justice & $3 \%$ & $2 \%$ & $6 \%$ \\
\hline Takafu? & Equity & $3 \%$ & $2 \%$ & $1 \%$ \\
\hline Musawaah & Equality & $3 \%$ & $6 \%$ & $5 \%$ \\
\hline Jur?ah & Guts & $3 \%$ & $2 \%$ & $2 \%$ \\
\hline Hoqooq & Rights & $3 \%$ & $4 \%$ & $5 \%$ \\
\hline Islaah & Reforms & $\ldots$ & $1 \%$ & $13 \%$ \\
\hline & & $39 \%$ & $35 \%$ & $61 \%$ \\
\hline
\end{tabular}

As can be seen from table (2) words that connote promises of making a change, like fighting corruption, equity, equality, justice and reforms, which come as responses to demonstrators' calls and slogans, were more recurrent in the advertisements of 2013 than in the other two elections with a percentage of $61 \%$ in 2013 compared to 39\% and 
35\% in 2007 and 2010 respectively. The expression fighting corruption has the highest percentage of recurrence, $15 \%$, followed by the word change with a recurrence of $13 \%$. Fighting corruption in particular acquires a more serious meaning in 2013 advertisements as it comes after corruption scandals that have been unfolded during the uprisings and which have been one of the main reasons behind the political movements in the region. The table shows that the expressions that were most frequent in 2007 and 2010 turned out to be the least recurrent in 2013 for example, better future dropped from $9 \%$ in 2007 to $0 \%$ in 2013, and a promise and a vow, from $6 \%$ and $4 \%$ in 2007, 2010 respectively to 1\% in 2013 with similar results for poverty and hunger. And those with low percentages turned out to be the most frequent expressions in 2013. For example, fighting corruption soured out from 3\% in 2007 and 2\% in 2010 to 15\% in 2013, justice and equality also scored a higher percentage in 2013 to reach 6\% compared to $3 \%$ in 2007.

These figures indicate a serious shift in the focus of the advertisements of the three elections. Whereas 2007and 2010 election advertisements do not reflect much concern about political issues, those of 2013 reflect great interest in political change and reforms. It does not, however, mean that the candidates are really serious in their claims. They use expressions that reflect the public wishes of political change, and they do that just to win their votes. The focus on political issues is shown to be very low in 2007 and 2010 advertisements. However, they manifested a concentration in the use of expressions that connote economic issues. A recurrent theme in these advertisements is poverty. Table (3) shows the recurrence of poverty synonyms.

Table (3) Frequency of Synonyms of poverty in the advertisements of the three elections 2007, 2010 and 2013

\begin{tabular}{|l|l|l|l|l|}
\hline $\begin{array}{l}\text { Lexical Item } \\
\text { Arabic }\end{array}$ & English & $\begin{array}{l}2007 \\
\%\end{array}$ & $\begin{array}{l}2010 \\
\%\end{array}$ & $\begin{array}{l}2013 \\
\%\end{array}$ \\
\hline ?qtisad & Economy & $3 \%$ & $2 \%$ & $1 \%$ \\
\hline Khubz & Bread & $3 \%$ & & $1 \%$ \\
\hline Faqer/joo & Poverty and hunger & $6 \%$ & $5 \%$ & $2 \%$ \\
\hline Khidmah & Service & $9 \%$ & $4 \%$ & $3 \%$ \\
\hline & & $21 \%$ & $11 \%$ & $7 \%$ \\
\cline { 5 - 6 } & & & &
\end{tabular}


Synonyms of poverty which are, generally speaking, used in all election advertisements, dropped from 21\% in 2007 to 11\% in 2010 and 7\% in 2013 advertisements. This is not, however, an indication of economic development. Rather it is an indication of a shift in attention. In 2007 elections, money played a crucial role in motivating people to vote. The miserable economic situation and the absence of opposition parties who boycotted the elections, thanks to the single vote system, resulted in lack of political interest on the part of both candidates and voters and created a sort of disbelief in the whole process of democracy. Realizing this, the candidates focused on narrow individual issues to win their votes. And so expressions like fight for bread, job opportunities, improving economy, together with promises of giving donations and hiring people, were distinguishing features of 2007 and 2010 elections. However, as the table shows in 2013 the financial interest seems to be much less than it used to be in previous elections. This shift in focus is, probably, a result of the public awareness of other needs that may result in improving people's life in general, such as freedom, justice and equality which guarantee a proper distribution of resources. This is manifested in the selection of lexicons including collocations. The analysis shows a difference in the selection of the collocations in the advertisements of the three elections. All the collocations in the advertisements of 2013 elections revolve around political change. The expressions fighting favoritism, fighting corruption, achieving justice, achieving equality, integrity and credibility and clean hands, free thought, safety and stability were all used in the advertisement of 2013, and they all reflect people's wishes of a democratic way of living. These expressions represent a call for democracy and political change. At the same time they imply accusations of corruption to those who run the country and collocate with people's doubts about the integrity of the people in charge of running the country. The word change (which is one of the words that occurred in the three elections) was used vaguely and loosely in the elections of 2007 and 2010 to refer to anything (i.e. social change, political change, or economic change). In 2013, the word change referred mainly to political reforms. This is the researchers' interpretation supported by her observation as a member of Jordanian society who witnessed the three elections. It is also supported by the analysis of the collocations used in the 
advertisements which shows that words like reforms, reformation, power exchange, fighting corruption, and fighting personal connections which all collocate with change are the most recurrent words in 2013 elections.

\subsubsection{New emerging words}

Not only has the recurrence of common words changed, but also new terms that had never been used in previous elections are observed in 2013 election advertisements. Words like democracy, free thought, and power exchange were taboos before 2013. No one would dare hinting at the leadership. But after the spring of 2011, criticizing the leadership and the government has become very common. Calls for Safety, stability, credibility, integrity, cleanness that imply accusations to the people who run the country, are among the recurrent words in the advertisements of 2013 election. This reflects people's revolutionary feelings. They are now more than ever before ready to fight for dignity, freedom, justice, and free thought. It must be noted however that recently the fear of encountering the same dreadful destiny as that in some neighboring countries made people give stability priority over freedom.

Most candidates in the 2013 elections posted their photos without slogans. This is due to two facts: First most of them were ex-members of the parliament, and their voters were guaranteed, and second most undecided people lost their trust in what the candidates say. They saw their slogans as empty words. However, when they used a slogan, candidates made sure to choose their lexicons carefully to convince people of their determination to bring a change. That is why words that connote narrow patriotism and loyalty to leadership were used less frequently in 2013 than in 2007. 


\subsubsection{Visual techniques ${ }^{3}$}

The analysis has also shown that there were differences in experiential values in the three periods at the visual level. Symbolic images have been used in the three elections but their recurrence varied. In the advertisements of 2007 and 2010 the visual elements occupied larger spaces than in those of 2013. In the latter, symbolic images almost disappeared from the advertisement by individual candidates; only the personal photo was used. However, in collective national lists (which were supposed to be party lists but then turned out to be collections of independent individuals) some symbolic images were used. Table (4) shows the symbolic images used in the three elections in percentages and their representations.

Table (4) Visual techniques in the advertisements by independent candidates before and after the Arab Uprisings in Jordanian society

\begin{tabular}{|l|l|l|l|l|}
\hline Symbol & Representation & 2007 & 2010 & 2013 \\
\hline Photo & Identification & $94 \%$ & $100 \%$ & $100 \%$ \\
\hline Traditional clothes & Belonging & $3 \%$ & $3 \%$ & $3 \%$ \\
\hline Flag & Nationalism/patriotism & $21 \%$ & $12 \%$ & $3 \%$ \\
\hline Crown & Loyalty to king & $15 \%$ & $0 \%$ & $0 \%$ \\
\hline unity map & Patriotic unity & $9 \%$ & $0 \%$ & $0 \%$ \\
\hline Flowers & Women & $6 \%$ & $0 \%$ & $0 \%$ \\
\hline Pictures & Loyalty to places & $6 \%$ & $0 \%$ & $0 \%$ \\
\hline
\end{tabular}

As shown in Table (4), in 2007 election advertisements, symbolic images prevailed in almost every ad. Symbols like the crown, the Jordanian flag, the Jordanian map, images of sacred places like Al-Aqsa Mosque, Castles, pictures of places and natural

\footnotetext{
${ }^{3}$ For the visual images in the advertisements of the three elections see the Annex
} 
landscape, wearing traditional clothes and using images of flowers were all used to connote certain meanings and attitudes. In 2010 the use of the flag represented only 12 $\%$ of all the images used in the sample data compared to $21 \%$ in 2007 and only 3\% in 2013. Symbols are either used to provide factual information or to provide symbolic meanings. Photos belong to the former. They are usually used for identification purposes, so their presence is obligatory in election advertisements. However, sometimes they are replaced by other images for social consideration. For example, in the advertisements of 2007 elections, when females nominated themselves for the first time under the quota law, some female candidates replaced their photos with flowers or images of places or objects that signify their electoral constituency (see Al-Momani 2012). This was done for social considerations. In some areas, namely rural areas, it is not socially acceptable that women publish their photos publically for fear of being misused. However, as shown in table (6), in 2010 and 2013 elections all the advertisements included personal photos for candidates including females. The table also shows that the use of most symbolic images that represent patriotism like the flag and the crown in the sample data has also dropped to 0\% in 2010 and 2013 in the sample data.

Very limited symbolic images, if any, were observed in 2013. They did not always connote specific meanings because they were mainly used for identification purposes. These symbolic images were used in the advertisement of the national lists. However, some lists chose symbols that have specific representations. Table (5) gives some examples of these.

Table (5) Examples of symbolic images and their representations used by national lists in 2013 elections ${ }^{4}$

\footnotetext{
${ }^{4}$ See the annex for these symbols
} 


\begin{tabular}{|l|l|}
\hline Symbol & Representation \\
\hline Photo & Personal literal identification \\
\hline Unity map & National unity/ Jordan and Palestine \\
\hline Flag & Patriotism/ belonging to Jordan \\
\hline $\begin{array}{l}\text { Dahnoon (A wild soft red flower } \\
\text { Jordan in Spring) }\end{array}$ & Patriotism/ belonging \\
\hline Book & Education \\
\hline Flame & Light \\
\hline Ghirbal Sieve & $\begin{array}{l}\text { Patriotism/ belonging/ Jordanian } \\
\text { folklore }\end{array}$ \\
\hline $\begin{array}{l}\text { Mihbash (traditional coffee } \\
\text { grounding wooden device) }\end{array}$ & $\begin{array}{l}\text { Patriotism/ belonging/Jordanian } \\
\text { folklore }\end{array}$ \\
\hline Shmagh (Men head cover) & Loyalty /belonging/Jordanian traditions \\
\hline
\end{tabular}

Although the verbal elements in the 2013 election advertisements reflect the new public demands and attitudes, the visual elements, when available, reflect slight attitudinal changes. Most images reflect patriotic feelings. For example, objects that represent Jordan, like images of specific flowers that grow in Jordan , and Jordanian traditions , like the images of traditional tools as the sieve and Mihbash (a wooden coffee grounding tool) or traditional clothes, are used to show loyalty to Jordan. Patriotic images that represent loyalty to the political system, like the crown, were of minimum use if any. This slight difference coheres with the verbal techniques that reflect a dramatic change in the lexical selection.

\subsection{Relational values}

Political advertisements aim at expressing the addresser's point of view towards certain issues in the surrounding world, changing the attitudes of audiences and affecting their passion to convince them to support the addresser. This is expressed in certain structures and linguistic tools that mark the relationship between the advertiser and the audience 
(i.e. candidates and voters). Thus relational values relate to the social relationships which are enacted via the text in the discourse (Fairclough, 1989). They are realized through modality, pronouns, and mood. As for modality the present tense and the future modal 'will', connoting necessity, certainty and determination are found to be commonly used in all advertisements. Candidates aim to reflect a high degree of self confidence and credibility, and one way of achieving this is through showing they are certain of what they say and believe. Examples include: I am with you; I am your strong voice; I will never let you down; I was ,I am , and will always be one of you. As for pronouns those of inclusion, such as $I$ and we, and exclusion, such as they, are obvious in the sample data.

These values reflect the social relationships between the participants which are evident in the practices of the candidates to emphasize solidarity, inclusion and exclusion which are confirmed by the language of the advertisement. The following discussion shows how these strategies are emphasized in the advertisements of the three elections.

\subsubsection{Inclusion}

Tribalism is an issue that plays an important role in Jordanian elections. Under the single vote system tribalism booms and gains priority. Votes go to the closest tribal candidate. So strategies of inclusion become an essential element of the slogans. Expressions like Ibnakum/ your son, and ibnatakum/your daughter mark an inclusion strategy and hence were used more liberally in the 2007, 2010 election advertisements than in 2013. Table (6) shows the different strategies of relational meanings 2007, 2010 and 2013 election advertisements.

Table (6): strategies of relational values in election advertisements before and after the Arab uprisings in Jordanian society 


\begin{tabular}{|l|l|l|l|l|l|}
\hline Elections & Inclusion & Exclusion & $\begin{array}{l}\text { Positive } \\
\text { self-image }\end{array}$ & $\begin{array}{l}\text { Voter positive } \\
\text { image }\end{array}$ & $\begin{array}{l}\text { Negative } \\
\text { other-image }\end{array}$ \\
\hline 2007 & $30 \%$ & $6 \%$ & $12 \%$ & $3 \%$ & embedded \\
\hline 2010 & $34 \%$ & $10 \%$ & $12 \%$ & $16 \%$ & embedded \\
\hline 2013 & $13 \%$ & embedded $^{5}$ & $2 \%$ & $7.5 \%$ & embedded \\
\hline
\end{tabular}

As shown in the table, candidates in 2007 and 2010 elections used more inclusion strategies than those in 2013 with the percentages of 30\%, 34\% and 13\%, respectively. Strategies of inclusion are realized through expressions that aim to leave the impression that the candidate is a member of the public. Expressions like your worry is my worry, your son/daughter, son of the tribe, son/daughter of the country, or addressing voters saying, My dear family and tribe, are only a few examples. Other inclusion expressions include those of patriotic expressions like we are all Jordanians. Inclusion techniques which aim at achieving solidarity include expressions like, hand in hand, together we can do it, together for justice, to be one of you and among you, and Jordanians together.

Visually, these verbal techniques are enhanced by images that complement the meanings. The use of traditional clothes is a clear message of belonging to confirm strategies of inclusion and solidarity. Your son /daughter, son/daughter of the north/south, and son/daughter of the tribe, daughter/son of Jordan, were complemented by pictures of famous places or natural landscape, maps and clothes worn by the members in the voting constituency, or by the tribe. Pictures that represent special places, like castles and mosques in the constituency, were also used to show loyalty to the place. Patriotic expressions like, we are all Jordanians, son of the country, or

\footnotetext{
${ }^{5}$ These strategies were not explicitly manifested in the verbal images but implicitly embedded in them.
} 
son/daughter of Jordan, are complemented by the Jordanian, unity map ${ }^{6}$ flag or the royal crown. However, in 2013 very few ads had elaborate inclusion expressions like, son/daughter of the tribe, and your son/daughter. In most advertisements visual images were confined to the candidates' photos. Only in very few cases the flag was used to mark patriotism.

\subsubsection{Exclusion}

The study has revealed two types of exclusion strategies. The first is self-exclusion which aims at leaving the speaker out to give the impression that he/she represents the public will, or works for the public interests rather than his/her own interests. This strategy is marked by using the pronoun your in expressions like, your candidate, the country and your rights are first, your voice. The use of your puts the speaker away from the action making the voters feel it is their choice and their will. Such strategies were more common in the advertisements of 2007 and 2010 than in 2013. The second is exclusion of the other, when other people are shown as separate from or against the public interests. Examples on this type of exclusion include, let's fight those who try to tamper with our security and unity, Let's fight the corrupt whoever and wherever they are and regardless of their positions. These examples carry within accusations of others as being evil people who do not care about the country, leaving the implication that the speaker is better. The use of 'they' and 'their' are markers of excluding those people. However, other-people-exclusion is not always expressed in such an obvious way. Rather in many cases, especially in 2013 advertisement, they are indirectly implied by other means. For example, the selection from Holy Quran, the Muslim’s sacred book, in 2013 was meant to exclude others who do not commit to Islamic law and are believed to have caused serious problems for Jordanians by their bad illegal conduct. So the verse,

\footnotetext{
${ }^{6}$ Unity map is formed with different hands in different colours holding together to form Jordan map
} 
"and stop them; they are to be questioned", is a call for suing corrupted people and punishing them. These are the words of God but adopted by the addresser in the context of elections to connote exclusion of others. Such excluding strategies and calls for fighting corruption and questioning 'others' who are involved in corruption scandals make allusions to the corruption scandals that were revealed in many Arab countries after the political movements in 2011.

\subsubsection{Creating positive and negative images}

Mood includes types of structure including declarative, imperative and interrogative. Declarative sentences are more recurrent in the data than imperative and interrogative sentences. In fact the imperative and interrogative are rarely used, and when used they are usually given in an indirect way. For example one way of using the imperative is through inclusion pronouns in the form of a suggestion, as in let us all work together /hand in hand for the interest of this country; or religious quotes like "and stop them; they are to be questioned". The interrogative mood has not been traced in the sample data. Most of the structures in the advertisements are in the declarative mood. One feature of the language of advertising is the use of short sentences or even phrasal expressions. Regarding the current study, short sentences and phrases have been observed both in the affirmative and negative modes in the advertisements of the three elections, as in yes for justice, yes for political reforms, no for corruption...etc.

Declarative sentences have also been observed through quotes and borrowings to create specific images of the different participants in the election process, as in the Qur'anic quote "I only intend reform as much as I am able". Within the framework of relational values, three different images are identified: Self-positive image, other-negative image and voter-positive image. These are the main representations in the different structures used in the sample data. The following section is devoted to the findings concerning these images.

\subsubsection{Self-positive image}

Creating a positive image is one aim of political advertising. Candidates try to create good images of themselves to leave a positive impression, and they express that in 
different ways, sometimes directly as in referring to themselves as, the voice of truth, the economic expert, a man of stances, and in using titles before names like, Doctor..., Engineer..., Lawyer...etc.', or indirectly in expression as, history is a witness, or by borrowing from sacred texts like Quranic verses that imply the good merits of the speaker like, the best to choose is the strong, the honest (6 Al Qasas), and I only intend reform as much as I am able (Hud 88). In the election advertisements before 2011 strategies of self-positive representation were obvious. Candidates paid a great effort in elaborating merits like education, positions, titles, achievements at all levels including the marital status and number of children which were sometimes used to show how committed and serious the candidate was especially in females' advertisements. Quotes from the Holy Quran were also among the techniques the candidates used to create a good image of themselves, not only by selecting verses that imply positive merits, but also to show they were religious people, since religious people, generally speaking, receive a lot of respect in Jordanian society (Al Momani 2010, 2012, Al Ali 2005, 2006). However, the table shows that only $2 \%$ of the selected data reflect explicit positive self- image in 2013 compared to $12 \%$ in the advertisements of each of 2007 and 2010 elections.

\subsubsection{Other-negative image}

Other-negative image is always implicitly embedded in the verbal and visual images. If someone describes himself/herself as loyal, this implies that others are not. So, expressions of positive self-image imply negative-other image. For example, your strong voice, implies that other candidates are weak and cannot speak up. Inclusion strategies also imply other-negative image. For example, to say, I am one of you and will always be with you, means that others are not. The table above shows an increase in using such strategies in the elections of 2010 and 2013, compared to 2007.

\subsubsection{Voter-positive image}

One of the relational functions of political advertisement is to create a positive image of the voters to make them feel better showing the value of themselves and the speaker's appreciation for them, and hence building rapport with them. The rationale behind this is that if somebody knows your value and appreciates you, he/she deserves your support. Such strategies include: flattering, praising, appreciating, thanking, and 
acknowledging. Examples of such strategies include: With you I become bigger, I am proud of you, You deserve better, your precious trust, oh, kind Jordanians, good people of ...+ (name of city), people of magnanimity and nobility. However, the 2013 advertisements reflected less use of voter-positive image with $7.5 \%$ compared to $16 \%$ in 2010.

\subsection{Expressive values}

Expressive values concern the producer's evaluation of reality relevant to his/her ideology (Fairclough 1989, p.119). The evaluation of the producers is reflected through the choices they make to persuade the audience. Besides lexical choice, intertextual borrowings play a very important role in this respect.

\subsubsection{Intertextual borrowings}

Election advertisement counts on the voters' schemata and experiences. So, one main feature of the three election advertisements in question is borrowings from different social and cultural sources. This includes personal experiences, historical references, religious references (mainly quotes from the Holy Quran and the Prophet's saying) and socio-cultural references derived from traditions and the status quo including chronic issues in Jordanian society (e.g. unemployment, poverty and inequality) Table (7) shows the most common sources of intertextual borrowings.

Table (7): Intertextual borrowings in the elections before and after the Uprisings in Jordanian society

\begin{tabular}{|l|l|l|l|}
\cline { 2 - 4 } \multicolumn{1}{c|}{} & 2007 & 2010 & 2013 \\
\hline $\begin{array}{l}\text { Religious } \\
\text { borrowing }\end{array}$ & $15 \%$ & $12 \%$ & $12 \%$ \\
\hline Poetic borrowing & $6 \%$ & $1 \%$ & $2 \%$ \\
\hline $\begin{array}{l}\text { Socio-cultural } \\
\text { references }\end{array}$ & $30 \%$ & $34 \%$ & $28 \%$ \\
\hline Political references & $6 \%$ & $16 \%$ & $25 \%$ \\
\hline
\end{tabular}


As shown in the table socio-cultural references form the majority of references in the advertisement of the three elections. Religious borrowings come second in the elections of 2007 with 15\% of frequency and third in 2010 and 2013 with 12\% for each. Political references have the most frequent use in 2010 and 2013 with $16 \%$ and 23\% respectively, but they were less frequent in 2007 with only 6\%. Poetic borrowings form the least in all elections. Below is an elaboration of these borrowings and references.

\subsubsection{Religious borrowings}

Religion is of great importance in Jordan. It influences all aspects of people's life and religious symbols are used by most people even unreligious ones (Narel 2012). Quranic verses are usually used as an opening in all genres of homely discourse in Jordanian society. They usually precede other elements since they are the words of Allah. In Islamic societies, it is believed that anything that starts with the words of Allah will be blessed and hence successful. However, using Quranic verses in political advertisement may have other connotations. Advertisements aim at convincing the voters of the credibility and good merits of the candidate that make him/her a respected person who can be trusted. Generally speaking, religious people in Jordanian society are supposed to have a high degree of honesty, credibility, integrity and firm stance since they follow the laws of Allah, and they do what they do for Allah's sake. Many candidates used religious references in a manipulative way. They may not be sincere in their faith, but they use Quranic verses to give a good impression and leave a positive effect on voters (for more information on the use of Quranic verses in political advertisements (see AlMomani 2012). The percentages of using Quranic verses were similar in the three elections with an increase of $3 \%$ in 2007, but the analysis has shown that each election reflected a different choice that matched the status quo at the time of each election. In 2007, there were no clear ideological views for candidates, so they chose verses that call 
for selecting the strong honest person who can handle the work he would be entrusted to. These were used in the three elections. The following are illustrative examples of some common verses in the advertisements of three elections ${ }^{7}$ :

(1) Wa qul i malu fasayara allhu amalakum wa rasolahu walmo?minu wa satoradduna ela alim alghaib washadati fayunabi?akum bima kuntum ta malun

And say, "Do [as you will], for Allah will see your deeds, and [so, will] His Messenger and the believers. And you will be returned to the Knower of the unseen and the witnessed, and He will inform you of what you used to do”. (Al Tawbah 105)

(2) Inna Khaira man ista?jarta Alqawiyu al?ameen

"Indeed, the best one you can hire is the strong and the trustworthy." (6 Al Qasas)

(3) Wa ma tawfiqi illa billah

“And my success is not but through Allah.” (Hud 88)

The first asks people to do what they do to please Allah. The second asks people to choose the strong, honest person to do jobs, and the third is just a prayer which indicates that the person depends first of all on Allah to achieve success. The same verses were used in the other two elections too. But some other selections were observed in the elections of 2010 and 2013. In 2010 new demands emerged as a result of the criticisms given to politician and to candidates' practices in the elections of 2007. So, candidates of 2010 added some other verses like those which call for questioning people and punishing the guilty ones, as in the following example:

(4) Wa qifuhum inahum mas?uloun

“And stop them; indeed, they are to be questioned” (Al-Saffat 24)

7 [all translations of Quranic verses were taken from "the translation of the holy Quran at: http://quran.com/9\#0] 
(5) Alhamdulilah allaðy bini matihi tatimu essalihat

"Praise be to Allah that His grace is righteous" (a prophet's saying)

In 2013, yet other verses were used that were relevant to the environment of uprisings and revolutions in the region. People demanded strict measures against corruption and the corrupt. In response to these demands some people were tried and sentenced, but some others were left loose. Calls for questioning those who committed the crime of robbing people and manipulated their source of living represented by high prices and law wages went louder. In light of this situation new verses were used that called for stopping and questioning those who betrayed people, and verses which reminded people of Allah's orders of honesty, justice and equality. The following are illustrative examples:

(6) Inna allaha ya?murakum an to?adu el?amanata ela ahliha wa itha hakamtum baina ennasi an tahkumu bil adl

'Indeed, Allah commands you to render trusts to whom they are due and when you judge between people to judge with justice'. (Al Nisa 58)

(7) In uridu illa el?islaha mastat a $t^{\prime}$

'I only intend reform as much as I am able.' (Hud 88)

(8) Allahuma eja?al Hatha albalada Aminan warzuq Ahlahu mina atthamarat man amana mihum billahi walyawm elakher

'My Lord, make this a secure city and provide its people with fruits - whoever of them believes in Allah and the Last Day.' (Al- Baqarah 125)

Religious borrowing is one of the common features in the genre of election advertisements. Quranic quotes are even used as a slogan in many cases. However, the analysis has revealed a difference in the selection of Quranic quotes in the three elections. In each election the selection reflects the status quo and people's wishes. In 2013 for example, the three quotes represent three main issues that worried people then. Quote (6) implies that the successive governments and decision makers were not honest and sincere with people. So it is a call and a promise to be honest, fair, just and trustful. Quote (7) is a call for reformation. This represents people's worries about the current political system and their call for political reformation, particularly the voting system. Quote (8) is a prayer to keep the country safe. Again this represents people's frustration, 
worries and fear that their country may encounter the same damage and destruction as that in some neighboring countries. Jordanians have learned from the Arab Spring that stability is now more precious than change, so people demand reform instead of revolution

\subsubsection{Poetic borrowings}

Poetic borrowings were another feature of the elections before 2013. They were not only used for aesthetic purposes, but also to connote feelings of patriotism and inclusion. The following verse is just a case in point.

(9) (law lam akun min al?urdun lwadatu law dafanoo foadi fi tharah alqani)

Had I not been Jordanian I would have wished to have my heart buried in its red soil [Researcher's translation]

In 2013, poetry was used for arousing feelings of heroism by choosing verses that show the candidate as a determinant strong powerful warrior. In such a confrontational atmosphere as that in the region now, a strong person is needed. The sword in the following extract is a symbol of power and strength.

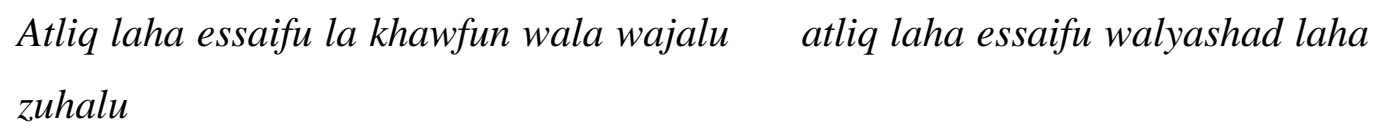

Atliq laha essaifu la khawfun wala wajalu atliq laha essaifu walyashad laha zuhalu

Release the sword no fear no fright release the sword and let Saturn watch [researcher's Translation]:

\subsubsection{Socio-Cultural references}

Cultural references are relevant to societal attitudes, stereotypes, traditions, customs, beliefs gender relations and the way of living. All these are reflected in advertisement through linguistic selection. Using titles (like Dr, Eng, Prof, etc.) before names, for example, is very important in Arabic culture. A person may gain respect by title more than by action. Personal merits and familial information are also other social features reflected in election advertisement. For example mentioning the marital status, the number of children, and level of education are among the cultural references that were 
used to give the impression that the person is serious, committed, responsible, and educated. Another cultural reference used in election advertisements is that of inclusion as in the use of your daughter/ son/ sister/ brother. Family bonds are strong in Jordanian culture, and family relations are culturally very important. A family supports and protects its members no matter what. Using expressions like "your son...or your daughter” aims at exerting intimate familial feelings.

\subsection{Textual values}

Textual values are realized through the organization and distribution of information in text. The analysis has shown that there were no remarkable differences between the three elections in terms of the generic patterns. The election advertisements of 2013 had more or less the same moves manifested in 2007 and 2010 elections, a matter which recognizes election advertisement as a genre with specific fixed moves (for more on generic features of political advertisement see Al-Momani 2012). This includes the following components: Opening, slogan, personal photo, name, number of constituency and symbolic images. Only few differences were revealed.

Table (8) shows the main generic components of advertisement in the three elections and the percentage of their recurrence.

Table (8) The generic components in 2007 and 2013 electoral advertisements

\begin{tabular}{|l|l|l|l|}
\hline Move & 2007 & 2010 & 2013 \\
\hline Opening & $18 \%$ & $8 \%$ & $4 \%$ \\
\hline Slogan & $90 \%$ & $90 \%$ & $60 \%$ \\
\hline Photo & $94 \%$ & $100 \%$ & $100 \%$ \\
\hline Name of & $100 \%$ & $100 \%$ & $100 \%$ \\
\hline $\begin{array}{l}\text { Number/name } \\
\text { constituency }\end{array}$ & $27 \%$ & $12 \%$ & $3 \%$ \\
\hline Symbolic image & & & $100 \%$ \\
\hline
\end{tabular}

As the table shows there are three obligatory moves in the three elections: Photo, name, and number /name of constituency. Slogans formed also an obligatory move in 2007 
with a percentage of $90 \%$. However in 2013, the percentage of using slogans dropped to $60 \%$. As for the distribution of these moves in most of the ads (top-down order), the opening comes first followed by the slogan and name. But in many cases the slogan may come in different places; it could come at the end or in the middle right after the name. As for the number and name of constituency they may come anywhere around the photo, at the bottom/top, on the left/right side/corner, usually inside a circle in numbers and sometimes in words (i.e. '5' or 'the fifth').

The opening could be a poetic verse, a proverb, a quote, or a Quranic verse. Quranic verses are commonly used as an opening in all social events in Jordanian society. Accordingly, almost all genres of homely discourse start with the verse 'in the name of Allah the merciful the compassionate'. In Islamic societies, Quranic verses usually precede any other element because, as mentioned above, it brings blessings and success. So, most of the advertisements in 2007, 2010 included Quranic verses in the opening move. Yet, the majority of the ads in the 2013 elections did not include the opening as an obligatory move, and when they did, it was usually a Quranic verse.

Table (8) shows a decrease in the use of slogans in 2013. Even when the advertisement had a slogan, a difference in the content of some of them was revealed, as was shown in the analysis of lexical choice above. In most cases they were also timidly written in small font as if they were meant to be invisible. This could be due to two reasons: First, because the atmosphere in the region was not suitable for making promises that cannot be fulfilled, like those made before, and second because about $30 \%$ of the candidates (according to a report by the Jordanian embassy in 2013) were ex-deputies, so their voters had already known them, and thus slogans were unnecessary. In 2007 and 2010, elegant, poetic and attractive slogans soared out, and the verbal elements occupied large spaces in posters. In 2010 advertisements too much talk and sometimes even chunks of language were used that one would get bored of the length of texts, especially newspaper advertisements. However, generally speaking, differences in the textual relation and meanings have been shown to be minimal. The ads of 2007, 2010, and 2013 have more or less the same generic features. 


\section{Conclusion}

The aim of this study was to investigate the influence of the uprisings and political movements which started in the spring of 2011 in the Arab world (known as the Arab Spring) on election advertisements in Jordan. Three elections were chosen for this purpose: 2007, 2010, and 2013 representing two periods, before and after the Arab Spring. The analysis has shown considerable linguistic differences at the experiential, relational, and expressive levels. Experientially, the analysis has shown considerable linguistic differences in the verbal techniques and their recurrence. Regarding lexical choice, the analysis has shown that most of the lexical items in 2007, 2010 were related to patriotism and socio-economic issues, like poverty and unemployment; whereas in 2013 elections, words related to socio-political issues were more prevalent. Bold slogans calling for reforms in the political system (not only in the voting system) were noticed for the first time in the history of Jordanian elections.

Relationally, differences in the type and recurrence of relational values via text in the advertisements of the three elections have been observed. Mood, modality tense and pronouns were all means of expressing relations between candidates and voters to build rapport, achieve solidarity and create certain images of the different participants. However, the advertisements in 2013 elections show a decline in the use of familial and tribal inclusion pronouns as well as in strategies of candidates' self-positive and voterpositive image representation. Quotes from sacred texts like the Holy Quran focused on honesty, trust, justice and reforms.

Expressively, the analysis of the intertextual choices which reflect the candidate's evaluative views shows a change in the selection of borrowings. Unlike the Quranic quotes in 2007, 2010 which focused on personal merits, in the advertisements of 2013 elections most of the religious quotes focused on fighting corruption and questioning authoritative people.

At the textual level, differences in the organizational pattern have been shown to be minimal. The advertisements of 2007, 2009, and 2013 had the same generic features and the same distribution of information. The difference that has been observed concerns the recurrence of obligatory and optional moves. In the elections before 2013 there were six 
obligatory moves: Opening, slogan, photo, name, and number of constituency. Optional moves concerned the symbolic images. In the elections of 2013 the majority of the advertisements had only three moves: Photo, name, and number of constituency. The optional moves included the opening, slogan, and other symbolic visuals which were very limited. Even when the advertisement had a slogan, it was timidly written in small font. All in all minimal verbal elements were observed in the elections of 2013.

The researcher believes that the discourse of election advertisement has witnessed a considerable change in Jordanian society since 2011 which is seen as a turning point in the political arena in the Arab world and which has influenced every aspect of Jordanians' lives.

\section{References}

Al-Ali M. 2005. Communicating message of solidarity, promotion and pride in death announcement genre in Jordanian newspaper. Discourse and Society 16(1), 5-31.

Al Ali, M. 2006. Religious affiliations and masculine power in Jordanian wedding invitation genre. Discourse Studies 17 (6), 691-714

Al- Momani, Kawakib, Dana Alrefae. 2010. A Socio -Textual Analysis of Written Wedding Invitation in Jordanian Society. LSP 1, 1, http://rauli.cbs.dk/index.php/lspcog/article/view/2632.

Al-Momani, Kawakib. 2012. Schematic representations in election advertisements in Jordan. In Multimodal Texts From Around The World: Cultural and Linguistic Insights, Wendy Bowcher (ed.), 39-66. Palgrave Macmillan.

An, Daechun. 2003. Content Analysis of Advertising Visuals in the Magazine Advertisements: The Roaring Twenties and the Great Depression. WJMCR 6: 3 June 2003.

Bowcher, W. L. 2007. A Multimodal Analysis of Good Guys and Bad Guys in Rugby League Week, in Terry D. Royce, Wendy L. Bowcher (eds.), New Directions in the Analysis of Multimodal Discourse. Hillsdale, NJ, Lawrence Erlbaum, 239-274. 
Cheong, Y. 2004. The Construal of Ideational Meaning in Print Advertisement' in Multimodal Discourse Analysis: Systemic Functional Perspectives, (ed.) O’Halloran. London: Continuum, 163-195.

Fairclough, N. 1989. Language and Power. London: Longman.

Fairclough, N. 2005a. Critical discourse analysis and change in management discourse and ideology: a transdisciplinary approach to strategic critique, to appear in F Ramallo ed. Studies in Organisational Discourse, languageandglobalization.pbworks.com.

Fairclough, N. 2005b. Critical discourse analysis in trans-disciplinary research on social change: transition, re-scaling, poverty and social inclusion. Lodz Papers in Pragmatics 1, 37-58.

Goddard, A.. 2002. The Language of Advertising: Written Texts. Routledge

Iedema, R. 2003. Multimodality, Resemioticization: Extending the Analysis of Discourse as a Multisemiotic Practice, Visual Communication 2.1, 29-57.

Johnstone, B. 2008. Discourse Analysis. Blackwell publishing.USA

Kress, G. and Van Leeuwen, T. 2001. Multimodal Discourse: The Modes and Media of Contemporary Communication Discourse. Visual Communication 7.4, 472.

Merriman, J. 1996. A History of Modern Europe: From the French Revolution to the Present.

Mona Christophersen. 2013. Jordan’s 2013 elections: a further boost for tribes, Noref Report - March 2013, http://www.peacebuilding.no/var/ezflow_site/storage/original/application/3cfcb19 1c3644dd32cda0c2c3431d149.pdf.

Moriarty, S. 1986. The Role of Advertising. Proceedings of the 1986 IVLA Conference, Madison, WI, (International Visual Literacy Association), http://ar.scribd.com/doc/39279601/The-Role-of-Visuals-in-Advertisements.

Moriarty, S. E. 1987. A content analysis of visuals used in print media advertising. Journalism \& Mass Communication Quarterly 64, 550-554. 
Myers, G. 2003. Pictures, Words, and Facts in Academic Discourse. www.aelfe.org/documents/text6-Myers.pdf.

Narel, P. 2012. Symbols of Religious Identity in Jordanian Society. SIT Digital Collections, Independent Study Project (ISP) Collection, digitalcollections.sit.edu/cgi/viewcontent.cgi?article=2277\&context=isp.

O'Halloran, K. L. 2008. Systemic functional-multimodal discourse analysis (SFMDA): constructing ideational meaning using language and visual imagery. In Visual Communication 7.4, 443- 475.

Raskob, C. 2012. Jordanians Seek a Meaningful Democratic Voice. Berkley Center, George Town University, October 10. Accessed 30 ${ }^{\text {th }}$ November 2015 at: http://berkleycenter.georgetown.edu/letters/jordanians-seek-a-meaningfuldemocratic-voice

Rossiter J.R and L. Percy. 1983. Visual Communication in Advertising. In Information Processing Research in Advertising, ed. R.J. Harris. Hillsdale, NJ: Lawrence Erlbaum Associates.

Royce, T. D. 2007. Intersemiotic Complementarity: A Framework for Multimodal Discourse Analysis' in Royce and Bowcher (eds.), New Directions in the Analysis of Multimodal Discourse. Hillsdale, NJ, Lawrence Erlbaum.

Royce, T. D. and Bowcher, W. L. eds. 2007. New Directions in the Analysis of Multimodal Discourse, Hillsdale, NJ, Lawrence Erlbaum.

Sloan, D. W. 1991. Perspectives on Mass Communication History. Hillsdale, NJ: Lawrence Erlbaum.

Spath, A. and Makara, M. 2013. Elections in Jordan: Victory for Reform or More of the Same?, http://www.fpri.org/articles/2013/02/elections-jordan-victory-reformor-more-same.

Spindle, B. 2012. Jordanians Call for End to Monarchy. The Wall Street Journal. 16 November. 
Stockl, H. 2004. In Between Language and Image in Printed Media, in E. C. Charles and M. Kaltenbacher (eds.): Perspectives of Multimodality . Amsterdam: John Benjamins.

Unsworth L. 2007. Multiliteracies and Multimodal Text Analysis in Classroom work with Children’s Literature, in Royce \& Bowcher, (eds.) 331-359.

Van Dijk, T. 2005. Rhetoric of a little Ally: Political Implicature and Aznar's Legitimatization of the War in Iraq. Journal of Language and Politics 4.1, 65-91.

Werner, W. 2004. 'On Political Cartoons and Social Studies Textbooks: Visual Analogies, Intertextuality, and Cultural Memory’, Canadian Social Studies, 38.2, www.quasar.ualberta.ca/css.

Annex 1: Visual symbols commonly used in election advertisement in Jordan in $2007^{8}$

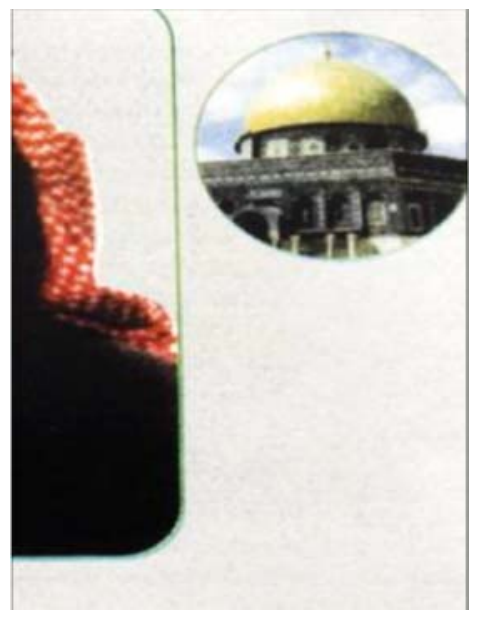

Fig 1. The Arab Kofiya (Jordanian traditional head cover for men in red and white; the black and white for palestinians) and Aqsa Mosque to represent unity between the two countries.

\footnotetext{
${ }^{8}$ It must be noted that faces and names accompanying the visual symbols have been concealed for the difficulty of obtaining permissions from candidates to publish their images and names.
} 


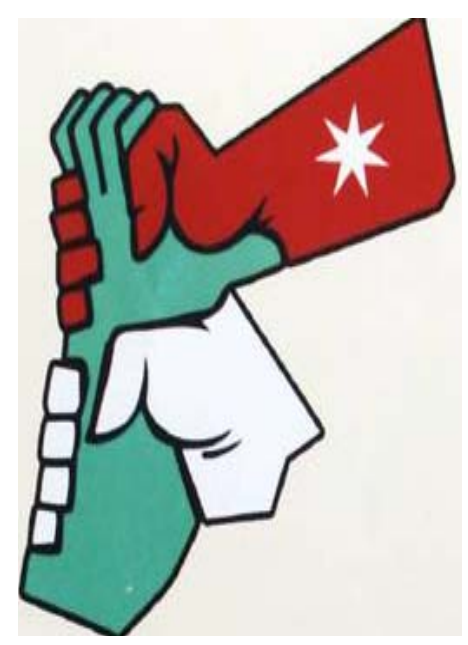

Fig 2. The Unity map of Jordan as a symbol of loyalty and patriotism in election advertisement.

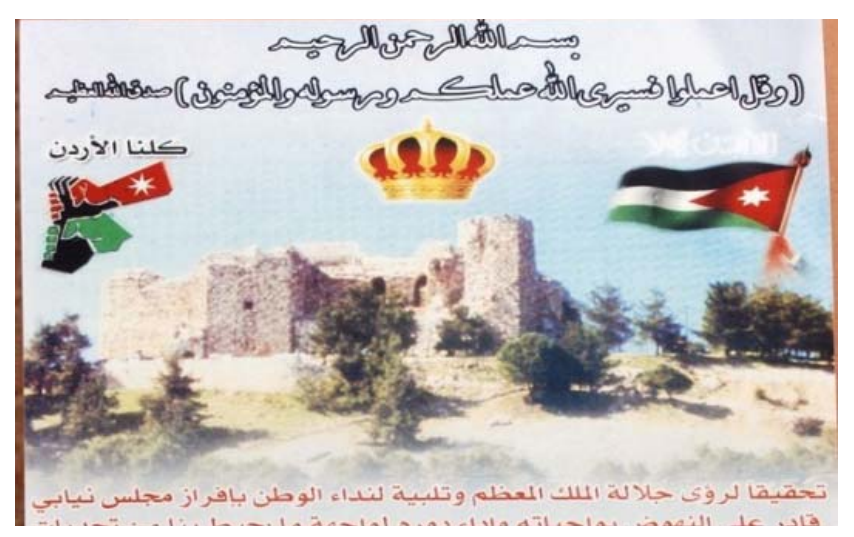

Fig 3. Symbolic images of patriotism: Jordanian flag, the royal crown, the unity map of Jordan.

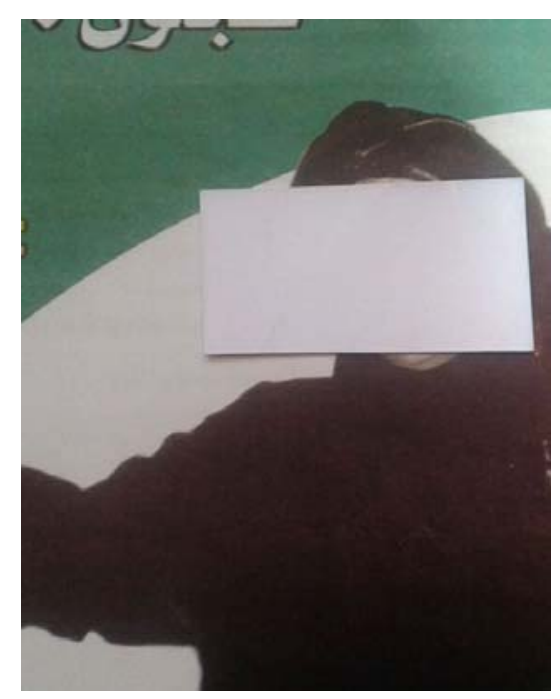

clac 65/2016, 3-43 
Fig 4. Jordanian female folkloric clothes to symbolize inclusion.

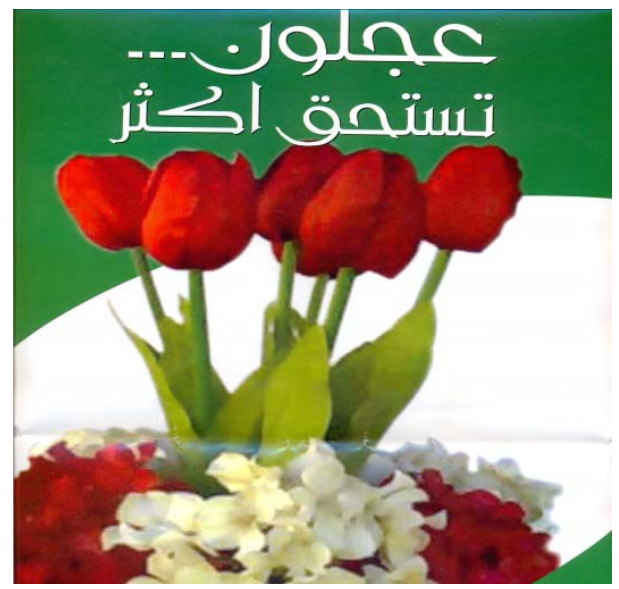

Fig 5. A picture of flowers replacing a female candidate's photo.

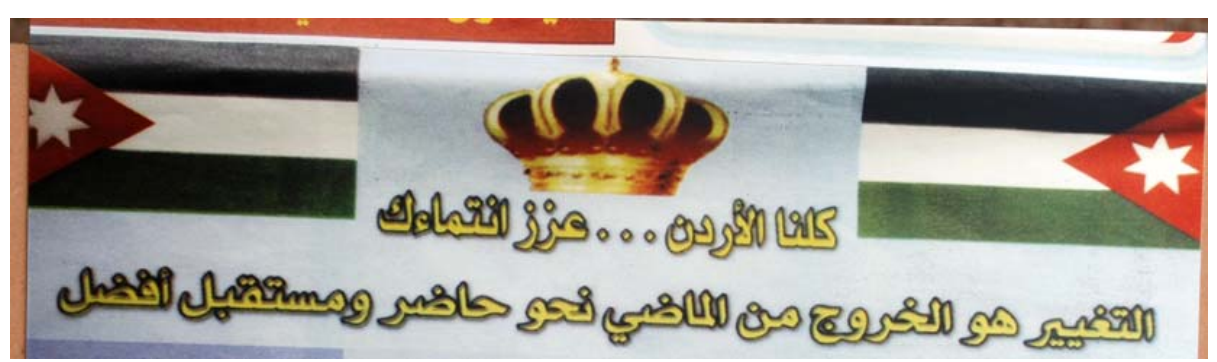

Fig 6. Jordanian flag and the royal crown.

Annex 2: Symbols in 2010 election advertisement in Jordan

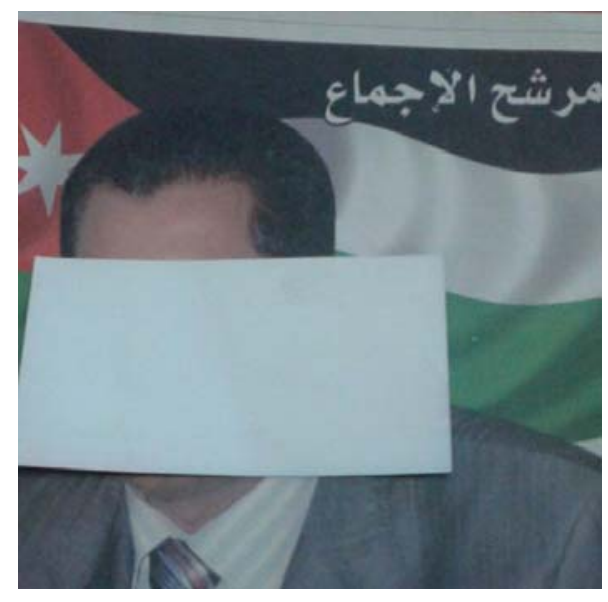

Fig 7. The Jordanian flag as a background to symbolize patriotism and loyalty. 


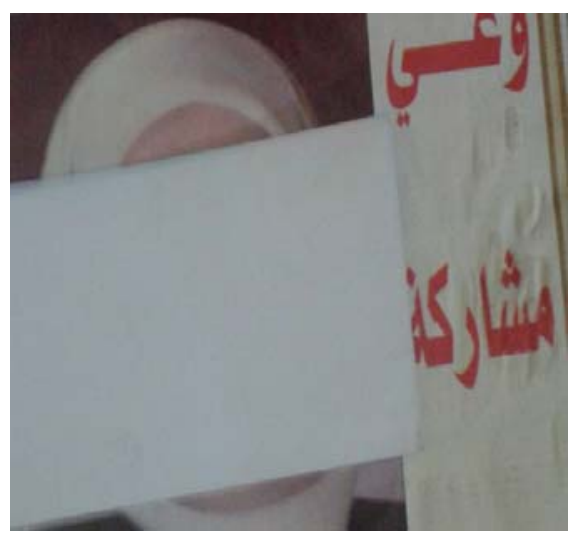

Fig 8. Hijab (Islamic female clothes) to represent religious commitment.

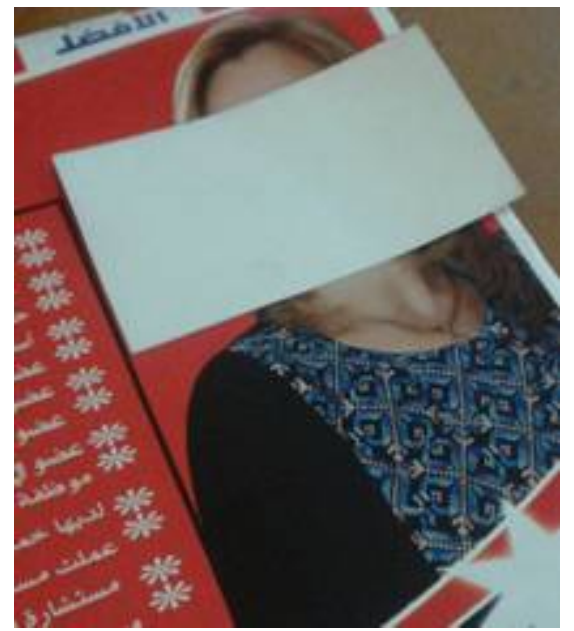

Fig 9. The Jordanian traditional dress as a symbol of inclusion.

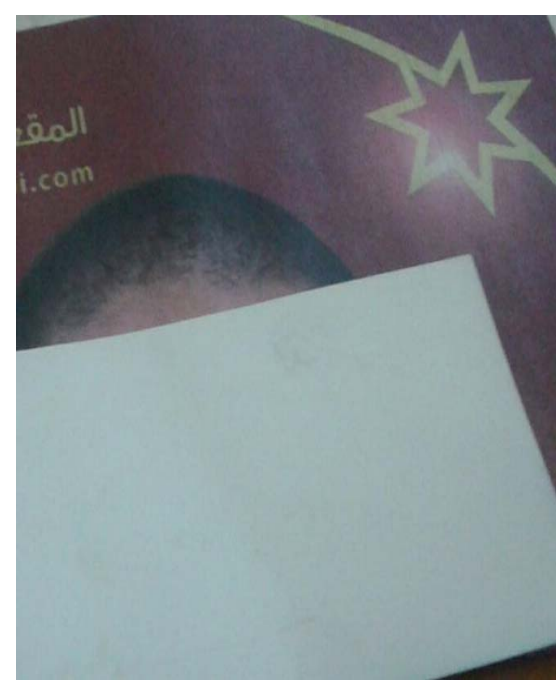

Fig 10. A star of the Jordanian flag without the flag to represent Arab nationalism as most Arab flags have a star in them. 
Annex 3: Symbols in 2013 election advertisement in Jordan

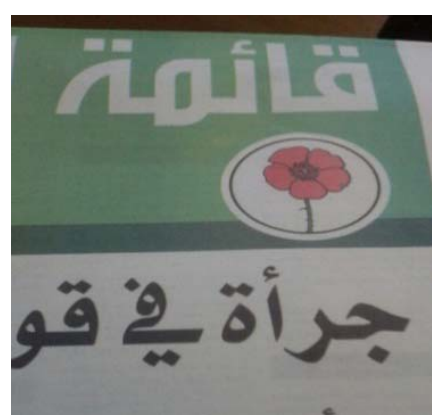

Fig 11. A flower as a symbol in in one of the national lists' advertisement.

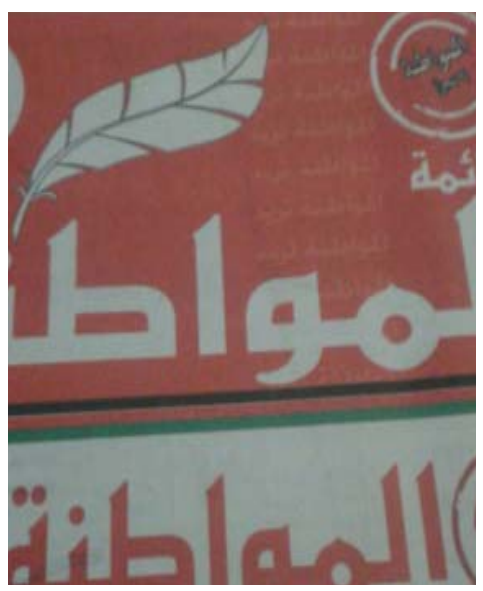

Fig 12. The feather as a symbol in one of the national lists' advertisement.

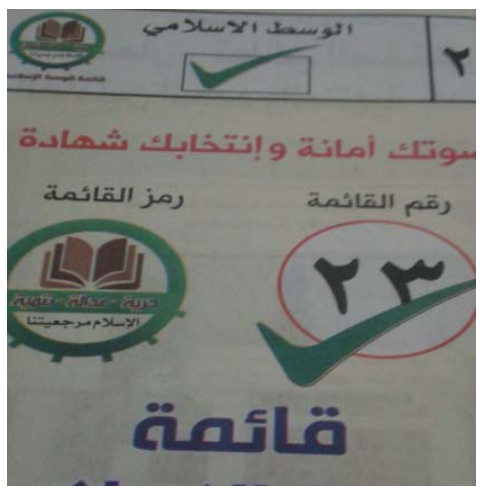

Fig 13. A book (presumably the Holy Quraan) as a symbols of a national list's advertisement. 


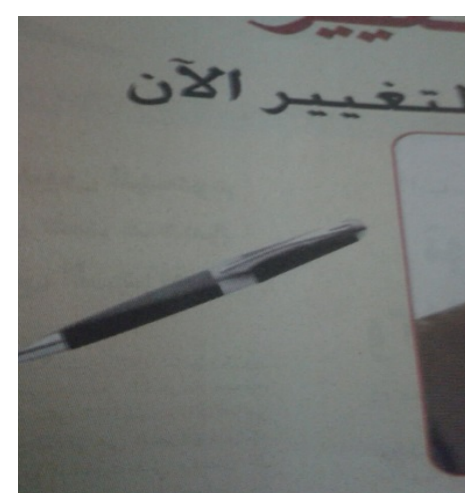

Fig 14. The pen as a symbol of a national list's advertisement.

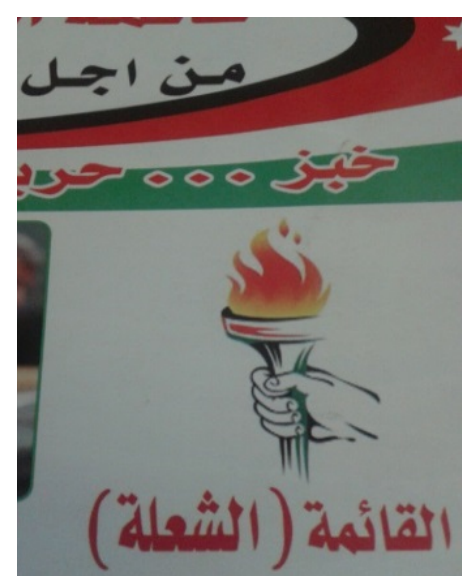

Fig 15. The Flame as a symbol in a list's advertisement.

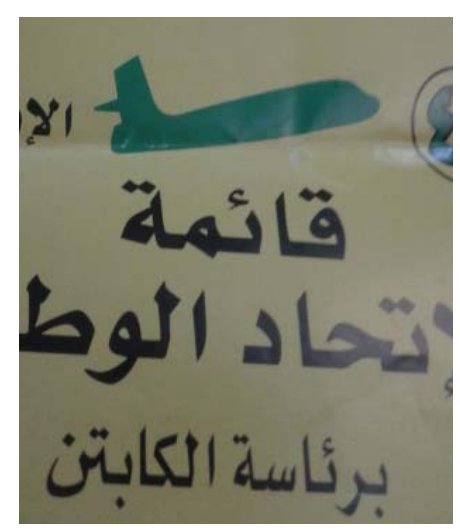

Fig 16. The plane as a symbol in a national list advertisement. 


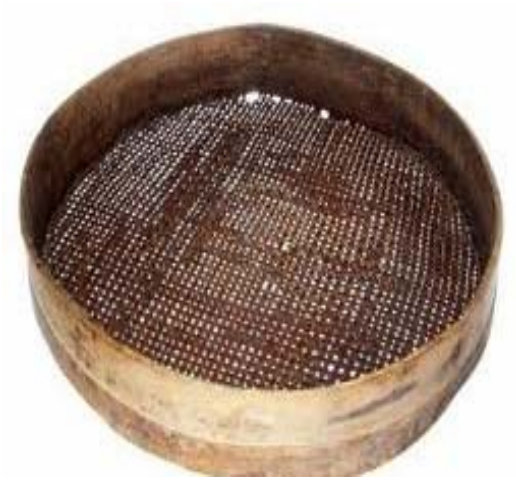

Fig 17. A traditional sieve Jordanian folklore representing loyalty to Jordanian heritage.

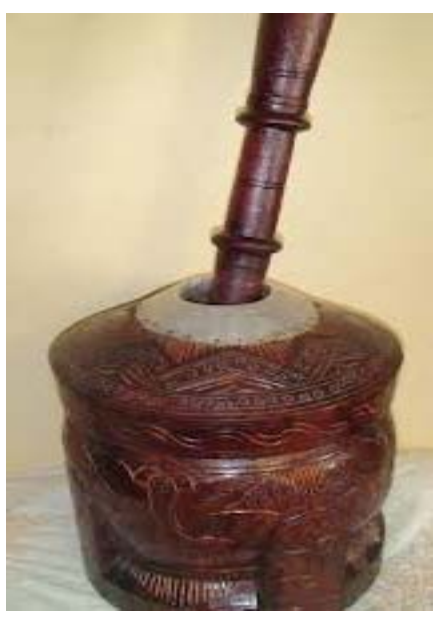

Fig 18. Mihbash (Traditional coffee grounder) representing loyalty to Jordanian heritage.

Received: December 19, 2014 Accepted: September 29, 2015

Published: February 29, 2016 Updated: March 2, 1016 